\title{
Article \\ Bioactive Carboxymethyl Starch-Based Hydrogels Decorated with CuO Nanoparticles: Antioxidant and Antimicrobial Properties and Accelerated Wound Healing In Vivo
}

\author{
Zahra Abdollahi ${ }^{1}$, Ehsan Nazarzadeh Zare ${ }^{1, * \mathbb{D}}$, Fatemeh Salimi ${ }^{2} \mathbb{D}$, Iran Goudarzi ${ }^{2}$, Franklin R. Tay ${ }^{3}$ \\ and Pooyan Makvandi ${ }^{4, *(D)}$ \\ 1 School of Chemistry, Damghan University, Damghan 36716-41167, Iran; zahra.yalda.abdollahi@gmail.com \\ 2 School of Biology, Damghan University, Damghan 36716-41167, Iran; f.salimi@du.ac.ir (F.S.); \\ irangoudarzi@du.ac.ir (I.G.) \\ 3 The Graduate School, Augusta University, Augusta, GA 30912, USA; tayfranklin7@gmail.com \\ 4 Istituto Italiano di Tecnologia, Centre for Materials Interface, Viale Rinaldo Piaggio 34, \\ 56025 Pontedera, Pisa, Italy \\ * Correspondence: ehsan.nazarzadehzare@gmail.com or e.nazarzadeh@du.ac.ir (E.N.Z.); \\ pooyanmakvandi@gmail.com (P.M.); Tel.: +98-2335220095 (E.N.Z.)
}

\section{check for}

updates

Citation: Abdollahi, Z.; Zare, E.N.; Salimi, F.; Goudarzi, I.; Tay, F.R.;

Makvandi, P. Bioactive

Carboxymethyl Starch-Based

Hydrogels Decorated with $\mathrm{CuO}$

Nanoparticles: Antioxidant and

Antimicrobial Properties and

Accelerated Wound Healing In Vivo.

Int. J. Mol. Sci. 2021, 22, 2531.

https://doi.org/10.3390/ijms22052531

Academic Editor: Jyh-Ping Chen

Received: 28 January 2021

Accepted: 26 February 2021

Published: 3 March 2021

Publisher's Note: MDPI stays neutral with regard to jurisdictional claims in published maps and institutional affiliations.

Copyright: (c) 2021 by the authors. Licensee MDPI, Basel, Switzerland. This article is an open access article distributed under the terms and conditions of the Creative Commons Attribution (CC BY) license (https:/ / creativecommons.org/licenses/by/ $4.0 /)$.

\begin{abstract}
In this study, nanocomposite hydrogels composed of sodium carboxymethylated starch (CMS)-containing CuO nanoparticles (CMS@CuO) were synthesized and used as experimental wound healing materials. The hydrogels were fabricated by a solution-casting technique using citric acid as a crosslinking agent. They were characterized by Fourier-transform infrared spectroscopy (FTIR), energy-dispersive X-ray spectroscopy (EDS), X-ray diffraction (XRD), field emission scanning electron microscopy (FESEM), and thermogravimetric analysis (TGA) to evaluate their physicochemical properties. In addition, swelling, antibacterial activities, antioxidant activities, cytotoxicity, and in vivo wound healing were investigated to evaluate the wound healing potential of the CMS@CuO nanocomposite hydrogels. Growth inhibition of the Gram-positive and Gram-negative pathogens, antioxidant activity, and swelling were observed in the CMS@CuO nanocomposite hydrogels containing $2 \mathrm{wt} . \%$ and 4 wt.\% CuO nanoparticles. The hydrogel containing 2 wt.\% CuO nanoparticles displayed low toxicity to human fibroblasts and exhibited good biocompatibility. Wounds created in rats and treated with the CMS@2\%CuO nanocomposite hydrogel healed within 13 days, whereas wounds were still present when treated for the same time-period with CMS only. The impact of antibacterial and antioxidant activities on accelerating wound healing could be ascribed to the antibacterial and antioxidant activities of the nanocomposite hydrogel. Incorporation of $\mathrm{CuO}$ nanoparticles in the hydrogel improved its antibacterial properties, antioxidant activity, and degree of swelling. The present nanocomposite hydrogel has the potential to be used clinically as a novel wound healing material.
\end{abstract}

Keywords: antibacterial; antioxidant; hydrogel nanocomposites; sodium carboxymethyl starch; $\mathrm{CuO}$ nanoparticles; wound healing

\section{Introduction}

Deprivation of nutritional factors adversely affects cellular differentiation, immune functions, and collagen formation that are vital for optimal wound healing [1]. An equally important factor for appropriate wound healing is the redox state of the wound tissue [2]. The redox state is preserved via an equilibrium between oxidant and antioxidant molecules. Oxidative stress occurs in tissues and cells when there is a disbalance between the reactive oxygen species (ROS) level and the antioxidant capability of the tissue or cells to eliminate ROS and repair the damage they cause [3-5]. Although ROS in low levels are crucial for the commencement and progression of wound healing, high ROS levels disrupt the 
cellular and molecular mechanisms involved in healing. This, in turn, causes cell death and disrupts the healing process [6].

Antioxidant compounds produce encouraging results in wound healing [7-9]. Antioxidants are species that deactivate ROS by donating their electrons to the ROS and preventing them from receiving electrons from vital molecules such as deoxyribonucleic acids (DNAs), proteins, and lipids [10]. Damage occurs when the level of antioxidant molecules is inadequate to protect the cells and tissue from oxidative stress [11]. Antioxidants act via enzymatic or nonenzymatic reactions that occur intracellularly or within organelles [12]. Chronic wounds in the human body possess high levels of oxidative stress [12]. Treatment of chronic wounds is often accompanied by local administration of antioxidants and antimicrobial agents to prevent infection of the wound site.

Natural polymers have attracted attention for wound treatment because of their biodegradability, biocompatibility, and non-toxic nature $[13,14]$. Starch is a low-cost, biodegradable natural polymer. Because of its low gel content, starch is incapable of forming a hydrogel without additional chemical and/or physical modification [15]. Carboxymethylation is a common method to improve the physical and mechanical properties of starch. Carboxymethylated starch (CMS) is a water-soluble starch derivative with a large number of carboxymethyl groups on the starch backbone [16]. This water-soluble starch version has been used extensively in the food industry [17], as well as for textile printing [18], drug delivery [19], and wound dressings [20].

The incorporation of metal oxide nanoparticles into natural polymers is often performed to improve the physicochemical, mechanical, and biological properties of polymers. Metal oxide nanoparticles possess outstanding properties in the regeneration of collagen. Many nanoparticles also possess antimicrobial and antioxidant properties [21]. Copper oxide $(\mathrm{CuO})$ nanoparticles have been used extensively in biomedical applications such as anti-cancer therapy [22], drug delivery [23], and wound healing [24] because of their biocompatibility, low toxicity, and antimicrobial properties [25].

Biologically-based nanocomposite hydrogels are valuable alternatives to commercially available synthetic wound healing materials. Antibacterial and antioxidative bio-based nanocomposite hydrogels that can accelerate the wound healing process are in heavy demand for soft tissue engineering applications. Previous studies have reported the use of hydrogels and nanocomposites films in wound healing applications [21,26-30].

In the present study, new nanocomposite hydrogels were designed to possess antimicrobial and antioxidant properties. Nanocomposite hydrogels consisted of sodium $\mathrm{CMS}$ as a natural polymer and $\mathrm{CuO}$ nanoparticles for the enhancement of in vivo wound healing (Figure 1). Different versions of the nanocomposite hydrogel were fabricated using the solution-casting technique and varying the concentrations of the $\mathrm{CuO}$ nanoparticles. The hydrogels were characterized by Fourier transform infrared (FTIR), energy-dispersive X-ray spectroscopy (EDS), X-ray diffraction (XRD), field emission scanning electron microscopy (FESEM), and thermogravimetric analysis (TGA). The antioxidant activity of different versions of the nanocomposite hydrogel was evaluated by the 2,2-diphenyl-1picryl-hydrazyl-hydrate (DPPH) free radical assay. The antibacterial activities, cytotoxicity, and in vivo wound healing potential were also examined. The null hypothesis to be tested was that there was no difference in the antioxidant activity, antimicrobial activity, and in vivo wound healing potential between hydrogels prepared from CMS incorporating $\mathrm{CuO}$ nanoparticles (CMS@CuO) and those prepared with CMS only. 


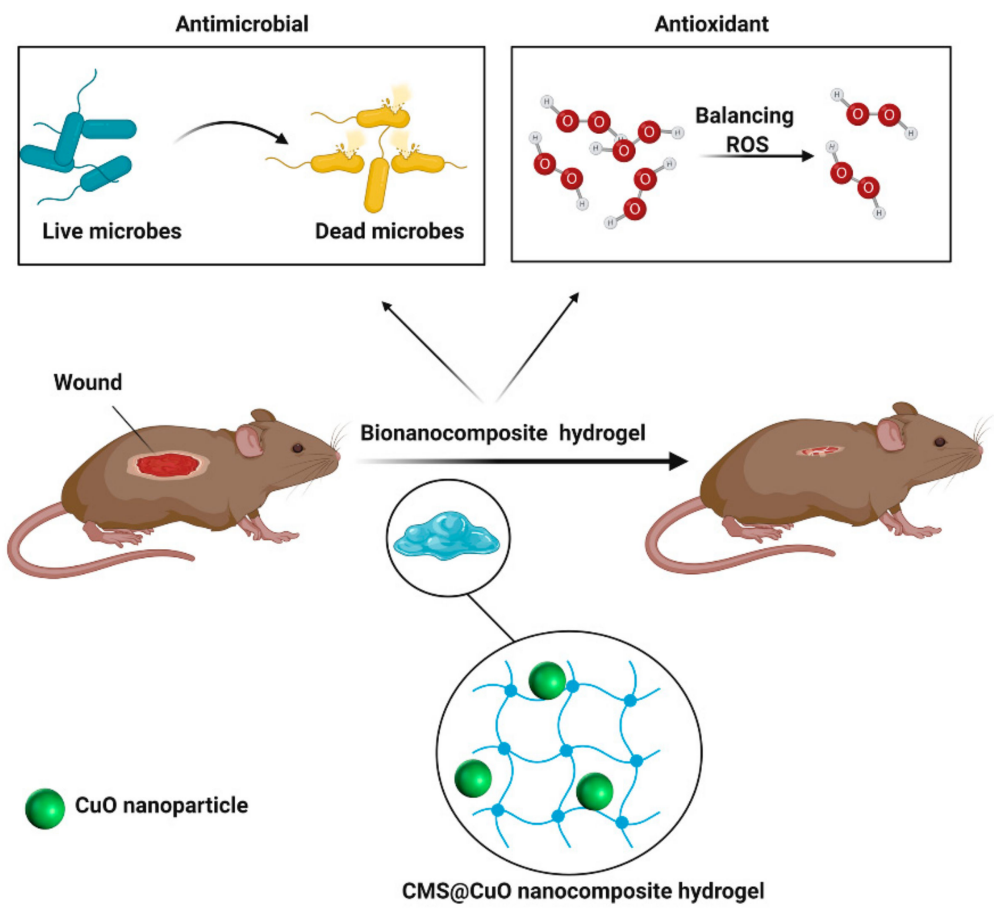

Figure 1. Schematic of the application of bioactive carboxymethylated starch (CMS)-containing $\mathrm{CuO}$ nanoparticles (CMS@CuO) nanocomposite hydrogel in wound healing. ROS: reactive oxygen species.

\section{Results}

\subsection{Characterization of Nanocomposite Hydrogel}

The infrared spectra of CMS, $\mathrm{CuO}$ nanoparticles, and CMS@2\%CuO nanocomposite hydrogel are shown in Figure 2a. In the FTIR spectrum of CMS, the broad peak around $3500 \mathrm{~cm}^{-1}$ was attributed to the stretching vibrations of $\mathrm{OH}$. Two peaks at $1601 \mathrm{~cm}^{-1}$ and $1420 \mathrm{~cm}^{-1}$ were associated with unsymmetrical and symmetrical stretching vibrations of the $\mathrm{COO}^{-}$, respectively. This result is in agreement with the literature [31,32]. In the spectrum of the $\mathrm{CuO}$ nanoparticles, two significant peaks that appeared at around $500 \mathrm{~cm}^{-1}$ and $605 \mathrm{~cm}^{-1}$ were attributed to the stretching vibration of $\mathrm{Cu}-\mathrm{O}[33,34]$. The peak around $1063 \mathrm{~cm}^{-1}$ was associated with the vibration of $\mathrm{OH}$, which indicates the presence of a large number of $\mathrm{OH}$ groups [33,34]. A wide peak appeared in the $3200-3500 \mathrm{~cm}^{-1}$ was ascribed to the stretching vibration of the $\mathrm{O}-\mathrm{H}$ group's surface $[33,34]$. The sharp peak that appeared at around $1610 \mathrm{~cm}^{-1}$ was attributed to the stretching vibration of $\mathrm{H}-\mathrm{OH}$ [34]. In the spectrum of CMS@2\%CuO, similar peaks related to CMS and $\mathrm{CuO}$ nanoparticles were observed, with slightly differences in intensity and peak positions because of the interactions between hydroxyl groups from the $\mathrm{CuO}$ nanoparticle surface and the CMS biopolymer matrix.

X-ray diffraction patterns of CMS, CuO nanoparticles, and CMS@2\%CuO nanocomposite hydrogel are shown in Figure 2b. The pattern of CMS was amorphous, when compared to the XRD pattern of starch (not shown). The reduction in crystallinity may be ascribed to the replacement of the $\mathrm{OH}$ groups by the $\mathrm{COO}^{-}$groups $[16,35]$. The result suggests that increase in the degree of substitution reduces crystallinity [16,35]. The pattern of $\mathrm{CuO}$ nanoparticles showed sharp peaks at $33^{\circ}, 35^{\circ}, 40^{\circ}, 43^{\circ}, 48^{\circ}, 50^{\circ}, 60^{\circ}, 65^{\circ}, 68^{\circ}$, and $75^{\circ}$. These peaks were related to (110), (002), (111), (112), (020), (202), (113), (310), (220), and (004) planes of $\mathrm{CuO}$ [36]. The sharp peaks that appeared in the diffraction pattern of $\mathrm{CuO}$ nanoparticles indicate that the synthesized $\mathrm{CuO}$ nanoparticles are highly crystalline with a monoclinic structure [36]. The XRD pattern of the CMS@2\%CuO nanocomposite hydrogel showed a semicrystalline nature. The peak at $31^{\circ}$ was ascribed to residual citric acid from esterification [37]. The low-intensity peaks that appeared at $35^{\circ}, 43^{\circ}$, and $75^{\circ}$ suggested that $\mathrm{CuO}$ nanoparticles were incorporated into CMS. 

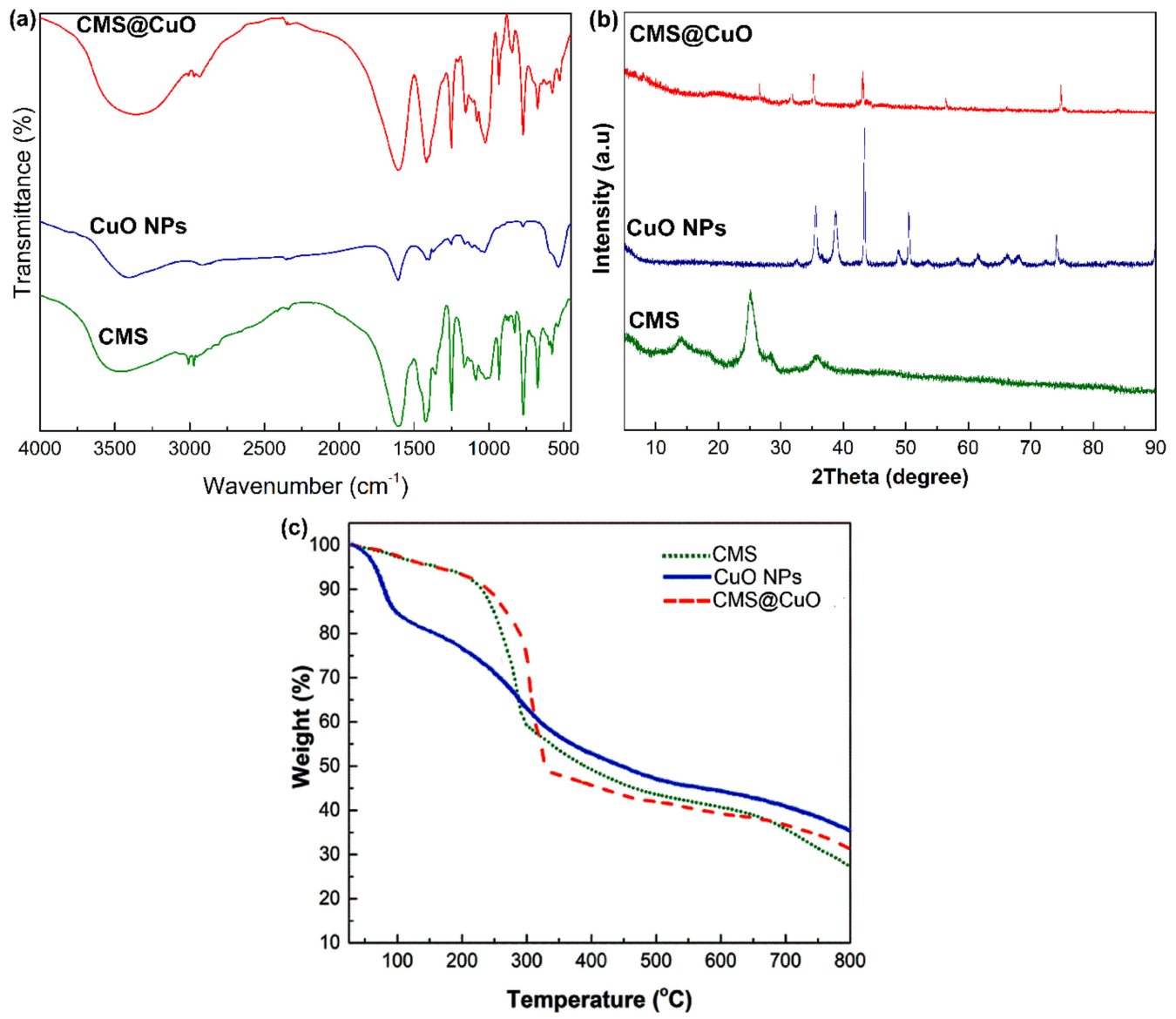

Figure 2. Fourier transform infrared (FTIR) (a), X-ray diffraction (XRD) (b), and thermogravimetric analysis (TGA) (c) of CMS, CuO nanoparticles, and the CMS@2\%CuO nanocomposite hydrogel.

The thermal stability of the $\mathrm{CuO}$ nanoparticles, CMS, and CMS@2\%CuO nanocomposite hydrogel was evaluated at a temperature range of $25-800{ }^{\circ} \mathrm{C}$ in an inert atmosphere. The TGA curves of the $\mathrm{CuO}$ nanoparticles, CMS, and CMS@2\%CuO nanocomposite hydrogel are shown in Figure 2c. Two major weight losses were observed on the TGA curve of CMS [38]. The first weight loss $\left(50-150^{\circ} \mathrm{C}\right)$ and second weight loss $\left(250-650{ }^{\circ} \mathrm{C}\right)$ were attributed to water evaporation and CMS decomposition, respectively. Carbonization and ash formation occurred at high temperatures (up to $650^{\circ} \mathrm{C}$ ) [38]. It has been reported that carboxymethylation reduced the thermal stability of starch materials [39]. In the TGA curve of $\mathrm{CuO}$ nanoparticles, $\sim 22 \%$ weight loss was seen in the range of $30-200{ }^{\circ} \mathrm{C}$, which was attributed to water evaporation. Approximately $40 \%$ weight loss was seen from $200{ }^{\circ} \mathrm{C}$ to $800{ }^{\circ} \mathrm{C}$, which was attributed to the organic matter decomposition of the specimen [40]. The CMS@2\%CuO nanocomposite hydrogel was thermally more stable than CMS. These results indicate that the incorporation of $\mathrm{CuO}$ nanoparticles into CMS increased the thermal stability of the nanocomposite hydrogel. In addition, the residual weight considerably increased after the incorporation of $\mathrm{CuO}$ nanoparticles into CMS. The residue weight of the $\mathrm{CuO}$ nanoparticles, $\mathrm{CMS}$, and CMS@2\%CuO nanocomposite hydrogel at $800{ }^{\circ} \mathrm{C}$ was around $40 \%, 29 \%$, and $35 \%$, respectively. The effect of a larger amount of $\mathrm{CuO}$ nanoparticles in FT-IR spectrum, XRD pattern, EDS spectrum, and TGA curve is shown in Figure S1 (Supplementary data).

Field emission scanning electron microscopy was used to examine the shape and size of the prepared materials (Figure 3a). The CMS appeared microscopically as irregular granules. The $\mathrm{CuO}$ nanoparticles were predominantly spherical with particle sizes between $30-50 \mathrm{~nm}$ in diameter $[35,41]$. The surface of the CMS@2\%CuO nanocomposite hydrogel appeared amorphous, with embedded agglomerates of $\mathrm{CuO}$ nanoparticles within the CMS 
matrix. Because of their high surface-to-volume ratio, nanoparticles tend to agglomerate to minimize their surface energy [42]. Agglomeration of the $\mathrm{CuO}$ nanoparticles accounts for the surface roughness of the nanocomposite hydrogel. This may be explained by the creation of a complex between the $\mathrm{CuO}$ nanoparticles and the $\mathrm{COO}^{-}$functionalities present on the CMS backbone. The surface roughness of the hydrogel is conducive to cell growth and proliferation by supporting cell attachment and secretion of the extracellular matrix [21].
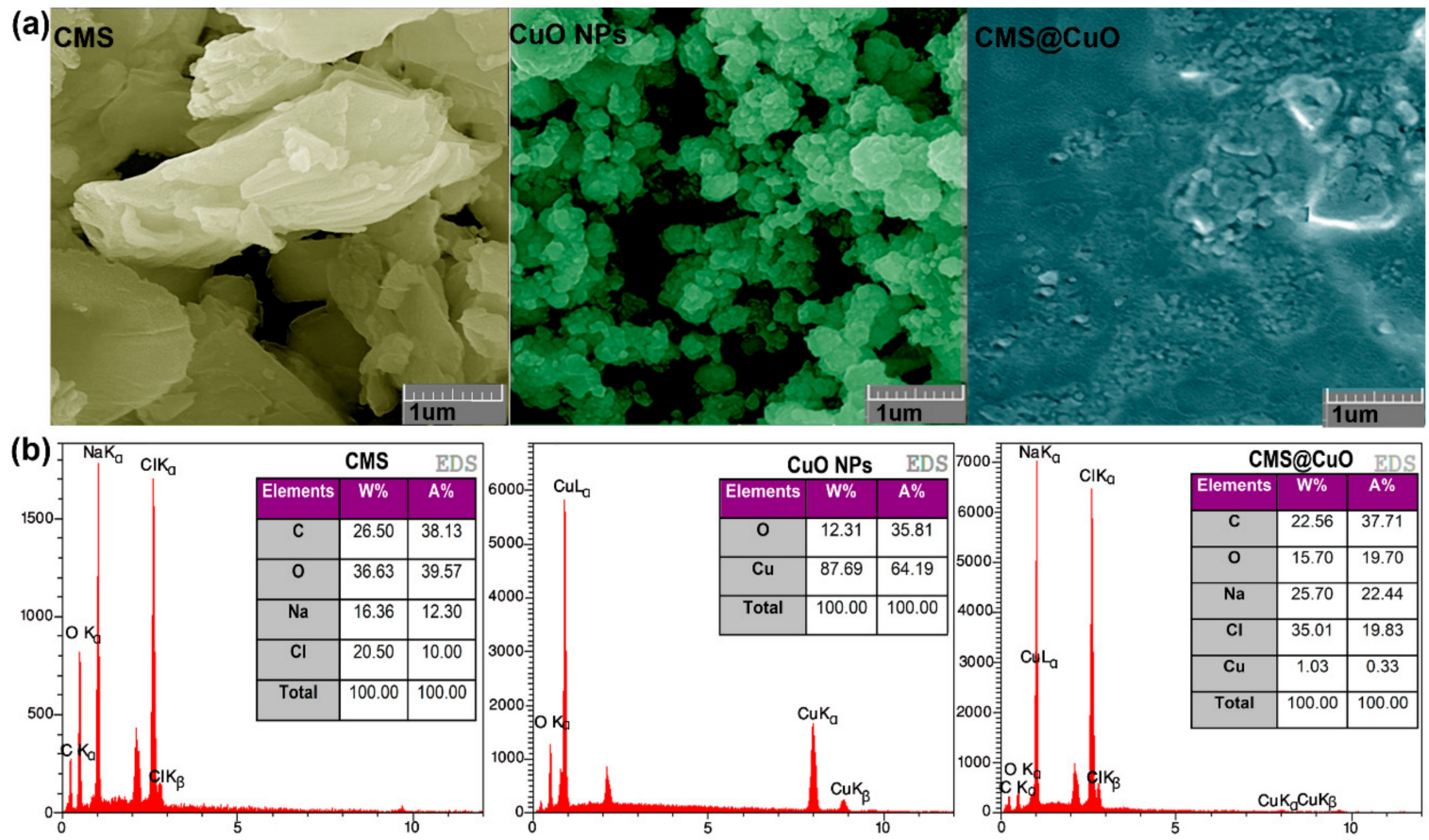

Figure 3. Field emission scanning electron microscopy (FESEM) images (a) and energy-dispersive X-ray spectroscopy (EDS) spectra and tabulated data (b) of CMS, CuO nanoparticles, and the CMS@2\%CuO nanocomposite hydrogel. CMS: carboxymethylated starch; NPs: nanoparticles.

The chemical composition of CMS, CuO nanoparticles, and the CMS@2\%CuO nanocomposite hydrogel was evaluated with EDS (Figure 3b). The existence of $\mathrm{Na}$ and $\mathrm{Cl}$ in the CMS specimens indicates that the biopolymer was successfully prepared. The presence of $\mathrm{Cu}$ in the CMS@2\%CuO nanocomposite hydrogel indicates that $\mathrm{CuO}$ nanoparticles were successfully incorporated into the hybrid hydrogel.

\subsection{Swelling Study}

The degree of swelling provides an indication of the extent of crosslinking of a hydrogel network. Figure $4 \mathrm{a}$ shows the degree of swelling of CMS, the CMS@2\%CuO nanocomposite hydrogel, and the CMS@4\%CuO nanocomposite hydrogel with a slow increase of the citric acid concentration within a $60 \mathrm{~min}$ period. At $15 \mathrm{wt} \%$ citric acid concentration, CMS had a swelling degree of $\sim 82 \%$. There was a drastic reduction of the degree of swelling at a high concentration of citric acid (i.e., $20 \mathrm{wt}$.\%). This was attributed to the creation of covalent bonds bridging the functional groups of the CMS chains and increasingly rigid hydrogel network. When $\mathrm{CuO}$ nanoparticles were added to the CMS matrix, the degree of swelling was higher than what was observed for the CMS hydrogel. This may be explained by the hydrophilic nature of the $\mathrm{CuO}$ nanoparticles. A higher degree of swelling of the CMS matrix enables faster absorption of wound exudates. This, in turn, keeps the wound dry and inhibit airborne infection. The degree of swelling of the hydrogel matrix was further augmented when the concentration of $\mathrm{CuO}$ nanoparticles increased from 2 wt.\% to 4 wt.\% in the nanocomposite hydrogel. These results indicate that $\mathrm{CuO}$ 
nanoparticles improve the swelling property of the CMS network in a similar manner as increasing citric acid concentration.
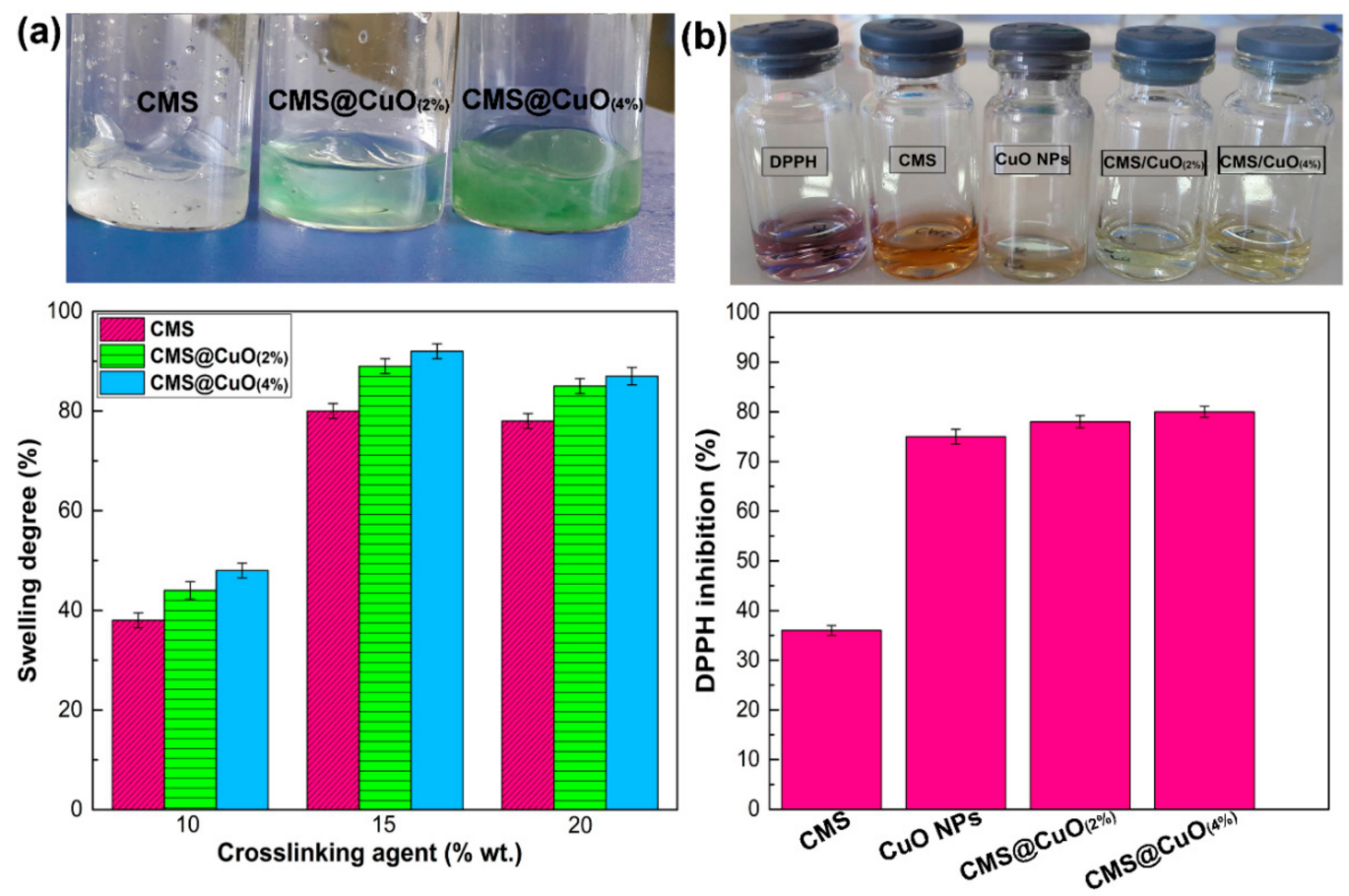

Figure 4. Histograms and photographs depicting the swelling behavior of the CMS hydrogel and the CMS@CuO nanocomposite hydrogels containing $2 \mathrm{wt} . \%$ and $4 \mathrm{wt} . \% \mathrm{CuO}$ nanoparticles. The histogram on the left shows swelling in the presence of different concentrations of citric acid as crosslinking agent (a). The histogram on the right and the photograph above show the antioxidant activity of CMS, CuO nanoparticles and the CMS@CuO nanocomposite hydrogels with 2 wt.\% and 4 wt.\% CuO nanoparticles (b).

\subsection{Antioxidant Study}

Skin is the primary barrier separating the body from the outside environment. Impaired wound healing is dangerous to the body. Delayed wound healing is observed in conditions such as old age and defects of the immune system [43].

In the inflammation phase of wound healing, leucocytes, neutrophils, and monocytes are attracted to the wound site. These immune cells secrete metabolites such as proteolytic enzymes, pro-inflammatory cytokines, and a large amount of ROS to protect the body against invading pathogens. Consequently, a low level of ROS is essential for optimal wound healing. However, high ROS concentration is detrimental because of the reactivity of these species, which adversely affect cellular mechanism. Healing of wounds or inflamed tissues under a respiratory burst condition is difficult because ROS such as hydroxyl radicals damage epithelial cells, proteins, and DNA. Previous studies have shown that the levels of antioxidants such as vitamin E, ascorbate, and glutathione are reduced (60-70\%) in inflamed tissues when compared with normal skin. This reduction is further aggravated in the aged, diabetics, and subjects with immunosuppression [44]. Many studies have shown, using in vitro assays such as the DPPH assay, that the application of exogenous and endogenous antioxidants is of value in accelerating wound healing [27,45-47].

Accordingly, the antioxidant potential of the nanocomposite hydrogel was evaluated using the DPPH assay. Figure $4 \mathrm{~b}$ shows the antioxidant activity of $\mathrm{CMS}, \mathrm{CuO}$ nanoparticles, the CMS@2\%CuO nanocomposite hydrogel, and the CMS@4\%CuO nanocomposite hydrogel. Data of antioxidant activity of tested samples are shown in Table S1 (Supplementary data). The color of the DPPH solution gradually changed from dark violet to light yellow, in the order CMS@4\%CuO > CMS@2\%CuO > CuO nanoparticles > CMS. This color 
change is reflective of the potent antioxidant properties of the materials used in the present study. The antioxidant activity of a material is related to its capability to provide an active hydrogen atom or transfer electron. Consequently, the chemical structure of the material plays a significant role in its antioxidant activity [48]. The antioxidant activity of CMS, CuO nanoparticles, CMS@2\%CuO, and CMS@4\%CuO after 60 min in a DPPH solution was $37 \%, 75 \%, 80 \%$, and $82 \%$, respectively (Figure $4 \mathrm{~b}$ ). The carboxylate group in the pyran rings of the CMS plays a vital role in antioxidant activity [48,49]. This result is in agreement with the antioxidant activity of polysaccharides such as sodium alginate and gum tragacanth, which contain carboxylate in their structures [48,49]. The $\mathrm{CuO}$ nanoparticles also demonstrated antioxidant activity because of the hydroxyl groups present on their surface. The antioxidant activity of $\mathrm{CuO}$ nanoparticles may be attributed to the transfer of electrons located on the oxygen atom to the odd electron located at the nitrogen atom in DPPH, thereby causing a decrease in absorbance at $517 \mathrm{~nm}$ [50]. Increasing the concentration of $\mathrm{CuO}$ nanoparticles from $2 \mathrm{wt} . \%$ to $4 \mathrm{wt} . \%$ resulted in augmentation of the antioxidant activity of the nanocomposite hydrogel. These hybrid hydrogels may be used for relief of oxidative stress at a wound site.

\subsection{Antibacterial Study}

The antibacterial potential of $\mathrm{CMS}, \mathrm{CuO}$ nanoparticles, and the nanocomposite hydrogels with $2 \mathrm{wt} . \%$ or $4 \mathrm{wt} . \% \mathrm{CuO}$ nanoparticles are reflected by the size of the inhibition zones against eight pathogenic bacteria in Figure 5. For the CMS, antibacterial activities against Gram-positive and Gram-negative bacteria were observed after $24 \mathrm{~h}$ of incubation with the diameter of inhibition zone between $20 \mathrm{~mm}$ and $32 \mathrm{~mm}$. Although pure starch does not have antibacterial activities [51], the presence of a carboxylate group in the CMS structure is probably responsible for its antibacterial activities. Copper oxide nanoparticles also exhibited antibacterial activities against the eight bacterial species, with the diameter of inhibition zones between $20 \mathrm{~mm}$ and $32 \mathrm{~mm}[52,53]$. The antibacterial activities of the $\mathrm{CuO}$ nanoparticles are attributed to ROS generation by the released metal ions, which cause malfunction of the bacteria cell membranes [53].

Incorporation of $\mathrm{CuO}$ nanoparticles into CMS significantly increased antibacterial activity against $P$. aeruginosa, S. aureus, S. enterica, Y. enterocolitica, and L. monocytogenes (in presence of $2 \mathrm{wt} . \%$ and $4 \mathrm{wt} . \% \mathrm{CuO}$ nanoparticles) $(p<0.05)$. The synergistic effect was higher for P. aeruginosa, Y. eterocolitica, and L. monocytogenes in the CMS@2\%CuO than the CMS@4\%CuO nanocomposites hydrogels. Taken together, the results indicate that the inclusion of antibacterial components (CMS and $\mathrm{CuO}$ nanoparticles) improves the antibacterial function of the hydrogel destined for wound healing.

\subsection{In Vitro Cell Cytotoxicity}

Cytotoxicity testing utilizes tissue cells in vitro to detect cell growth, proliferation, and morphological changes. Figure 6 represents the percentage cell viability of human fibroblasts that were cultured in presence of different concentrations of CMS, CMS@2 $\% \mathrm{CuO}$, and CMS@4\%CuO specimens (25-1600 $\left.\mu \mathrm{g} \mathrm{mL}^{-1}\right)$ after $24 \mathrm{~h}, 48 \mathrm{~h}$, and $72 \mathrm{~h}$. There was no significant difference in the viability of the fibroblasts after exposure to CMS at all concentrations examined after $24 \mathrm{~h}$ of incubation. The viability of CMS@CuO nanocomposite hydrogels was dose-dependent for all tested time periods. Cell viability decreased with increasing $\mathrm{CuO}$ nanoparticle concentration within the $\mathrm{CMS} @ \mathrm{CuO}$ nanocomposite hydrogels. Incorporation of $4 \mathrm{wt} . \% \mathrm{CuO}$ nanoparticles into the CMS resulted in significantly more severe toxicity when compared with CMS and CMS@2\%CuO after 24, 48, and 72 h of incubation. The effect of increasing $\mathrm{CuO}$ nanoparticle concentration on cytotoxicity has previously been reported [54]. The cytotoxicity of $\mathrm{CuO}$ nanoparticles is probably caused by an increase in ROS production, genotoxicity, and an increase in multi-xenobiotic resistance transport activity $[53,55]$. 

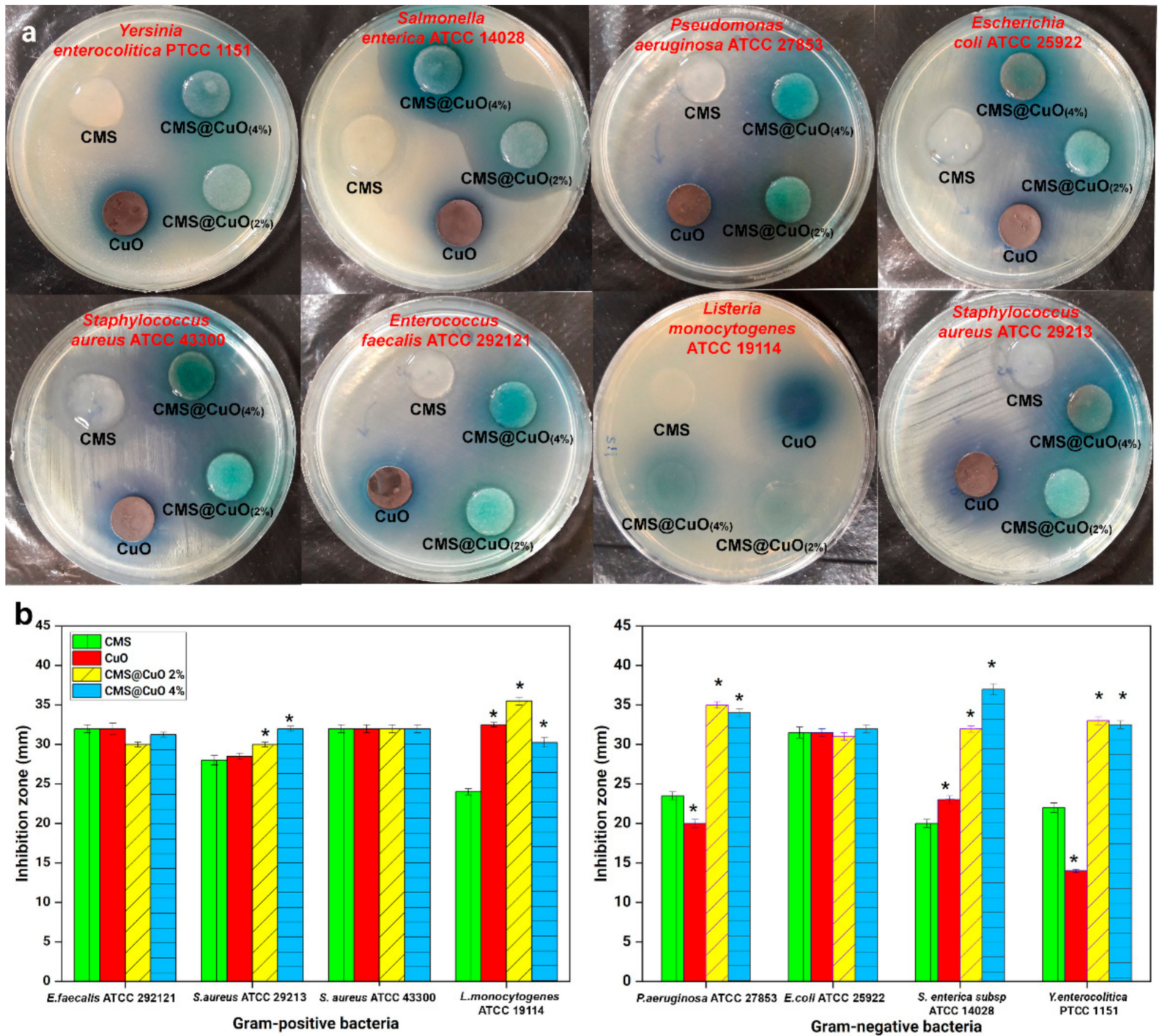

Figure 5. Antibacterial activity of CMS, CuO nanoparticles, the CMS@2\%CuO nanocomposite hydrogel, and the CMS@4\%CuO nanocomposite hydrogel against different Gram-positive and Gram-negative bacteria. (a) cell cultures (b) charts. For each chart, columns marked with asterisks $\left(^{*}\right)$ denote significant difference compared with pure CMS $(p<0.05)$.

\subsection{In Vivo Wound Healing Study}

Figure 7 shows the results of in vivo wound healing in a rat model. The extent of wound healing was significantly higher on day $5(p<0.05)$, day $7(p<0.01)$, day $9(p<0.01)$, and day $13(p<0.05)$ in the CMS@2\%CuO nanocomposite hydrogel-treated wounds, compared with those treated with the CMS hydrogel or the control group. A significant difference was observed in wound healing percentage between wounds treated with CMS and those treated with CMS@2\%CuO hydrogel on days 5, 7, 9, and 13. There was no significant difference in the wound healing percentage between wounds treated with CMS only and the control group. These results indicated that CMS@2\%CuO nanocomposite hydrogel accelerates wound healing. The control group had $31 \%, 46 \%$, and $79 \%$ wound healing on days 7,9 , and 13 , respectively, whereas the CMS@2\% $\%$ uO nanocomposite hydrogel group had $76 \%, 84 \%$, and $94 \%$ wound healing for the respective time periods. Wound length was measured on days $0,3,5,7,9$, and 13 after the creation of the wound. Wound length was significantly reduced in the CMS@2\%CuO hydrogel group on day 13 , when compared with the CMS group or the control group (Figure $7 \mathrm{~d}$ ). The findings indicate that wound healing 
in rats was accelerated with the use of the CMS@2\%CuO nanocomposite hydrogel as a wound dressing. On day 13, almost complete healing of the wound (94\%) was observed in CMS@2\%CuO hydrogel-treated wounds. In contrast, wound healing was only 82\% and $79 \%$ for CMS and control groups, respectively. Improvement in wound healing is likely attributed to the release of $\mathrm{Cu}$ (II) ion, an essential trace element with potent biocidal properties that promotes skin generation and angiogenesis [56,57]. Copper is believed to be involved in many processes related to wound healing. For example, angiogenesis is increased in the presence of copper (II) ions via induction of vascular endothelial growth factor production, enhancement of fibrinogen, and collagen stabilization, as well as an increase in the activity of the copper-dependent enzymes involved in matrix remodeling, cell proliferation and re-epithelization [57-59]. There is evidence that copper deficiency impairs the wound healing process [60]. Copper oxide nanoparticles produced by green synthesis have been reported to inhibit the growth of pathogenic bacteria on excision wounds and accelerated wound healing in rats [24]. The present findings are in agreement with the literature that copper oxide nanoparticles accelerate wound healing [24,61].
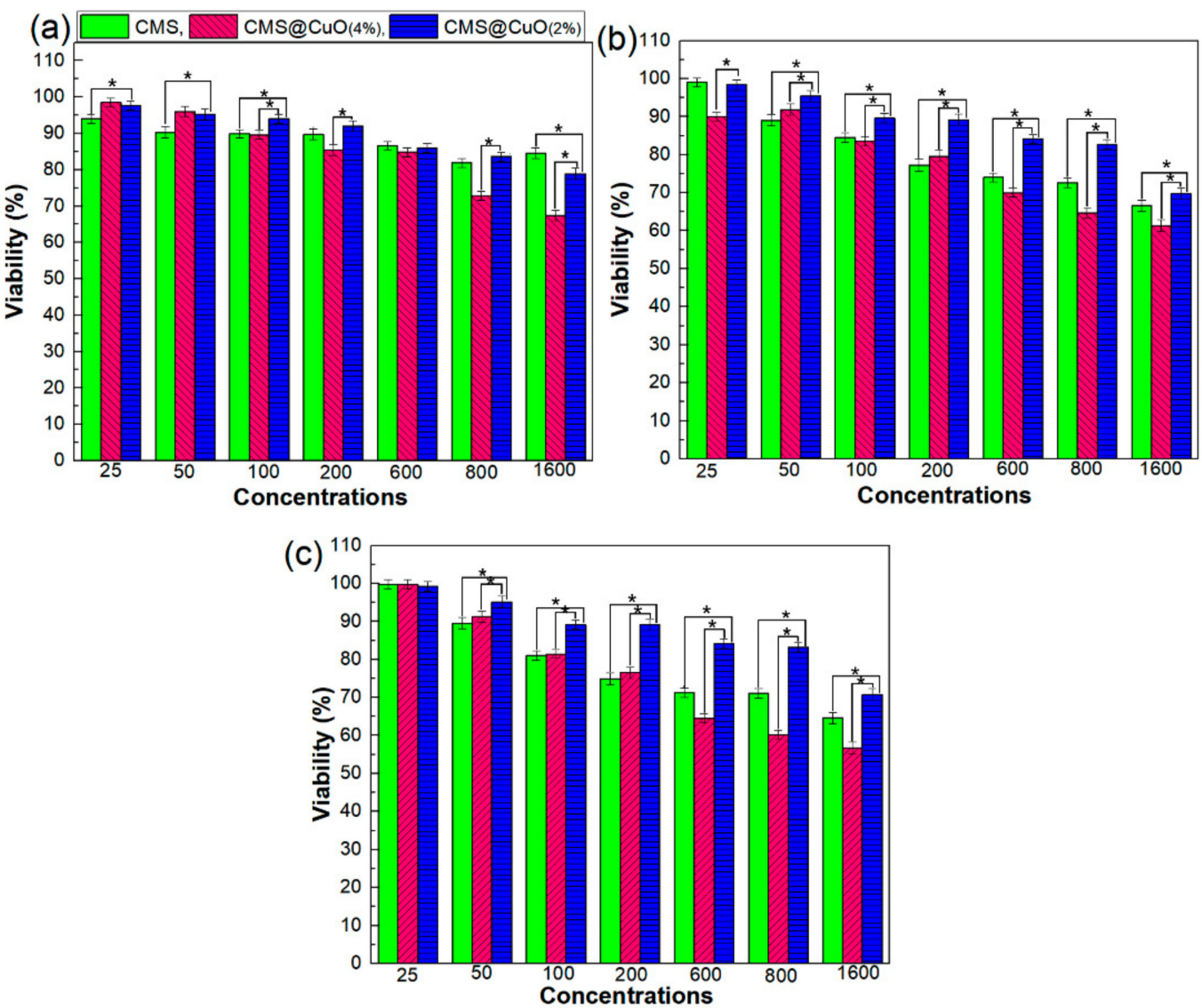

Figure 6. Cell viability (\%) of human fibroblasts after exposure to CMS, CMS@2\%CuO, and CMS@4\%CuO specimens in the culture medium for $24 \mathrm{~h} \mathrm{(a),} 48 \mathrm{~h} \mathrm{(b)}$, and $72 \mathrm{~h} \mathrm{(c).} \mathrm{Asterisks}\left(^{*}\right)$ indicate a significant difference $(p<0.05)$ between viability percent of treated cells with CMS@2\%CuO as most efficient hydrogel and ones treated with CMS and CMS@4\%CuO in one-way ANOVA test at a confidence interval of $95 \%$. 



Figure 7. Macroscopic photographs of the wounds treated with the control, CMS, and the CMS@2\%CuO nanocomposite hydrogel specimens at different time periods $(\mathbf{a}, \mathbf{b})$ and histograms of the percentage of wound healing (c) and wound length (d). For each chart, columns labeled with an asterisk $\left(^{* * *}\right)$ are significantly different from the control $(p<0.05$ and $p<0.01)$. 


\section{Discussion}

Wound care is essential in the elderly, as well as in diabetic and immunocompromised patients. When a wound is formed, microbes grow rapidly at the wound site. Depending on the type of the wound and its location, as well as how the wound is taken care of, the body initiates the wound healing process. The healing process may be interrupted by both external and internal agents. Four overlapping healing phases are involved in wound healing: hemostasis, inflammation, proliferation, and remodeling [62]. Microbial infections and ROS are important perturbing factors in the wound healing process and can prolong each healing phase, consequently resulting in structurally and functionally unsatisfactory results [63].

In healthy skin, the microbiota within this skin barrier is fairly stable. They through producing antimicrobial compounds and occupying various receptors on host cells limit invasion of pathogenic microbes. Although, commensal skin microbiota that exists beyond a critical threshold and microbial pathogens such as $S$. aureus, methicillin-resistant $S$. aureus, $P$. aeruginosa, and E. coli are among microorganisms which can cause infection in the wound site and adversely affect the initial phases of wound healing as well as healing of chronic wounds. When these microbial cells passed through the injured skin various innate and acquired immune cells such as dermal dendritic cells, macrophages, mast cells, T and B cells via various strategies try to remove pathogens. Agents with wound healing activity are used to accelerate healing and minimize wound-related complications. Although taking systemic antibiotics helps the body prevent microbial infections [64], the application of a locally-applied antimicrobial dressing on a wound is more desirable. Firstly, orally-administered antibiotics have to be metabolized in the gastrointestinal tract. Thus, a high concentration of antibiotics has to be taken for it to reach the wound site. Secondly, localized administration of antibiotics reduces microbial resistance to these drugs, which is a growing concern [43]. Pomades, gels, and ointments can kill the bacteria that multiplied at the wound site and may reduce the duration of treatment [65]. These types of materials are particularly useful in patients with diabetes, hepatitis, and acquired immune deficiency syndrome who have defective immune systems [66,67]. In the present study, the nanocomposite hydrogels investigated possess broad-spectrum antimicrobial activity and significant antioxidant ability. Results from the present study showed that the CMS and CMS@CuO hydrogels were able to kill eight species of Gram-positive and Gram-negative bacteria that are pathogenic to humans. When a wound is in the inflammatory phase, a large amount of ROS such as superoxide $\left(\mathrm{O}_{2}\right)$, peroxynitrite $\left(\mathrm{ONOO}^{-}\right)$, and hydroxyl radicals $(\mathrm{OH})$ are generated that damage the body's proteins and DNAs [6]. The use of antioxidant materials orally or topically can control ROS and prevent oxidative stress. Once the level of the antioxidant molecules is inadequate to protect the cells and tissues from excessive oxidative stress, delay in wound healing is inevitable [6,12]. The CMS@CuO hydrogels investigated in the present study have antioxidant properties that are higher than $75 \%$. The potent antioxidant activity enables the elimination of free radicals from the wound site. The in vivo data generated from the present study demonstrate that the application of these hydrogels as dressings in the wound site accelerates wound healing. These attributes synergistically support wound healing. Accordingly, the tested null hypothesis that "there is no difference in the antioxidant activity, antimicrobial activity, and in vivo wound healing potential between hydrogels prepared from CMS incorporating $\mathrm{CuO}$ nanoparticles (CMS@CuO) and those prepared with CMS only" has to be rejected. Figure 8 schematically illustrates the application of the nanocomposite hydrogel with antibacterial and antioxidant activity to promote wound healing. 


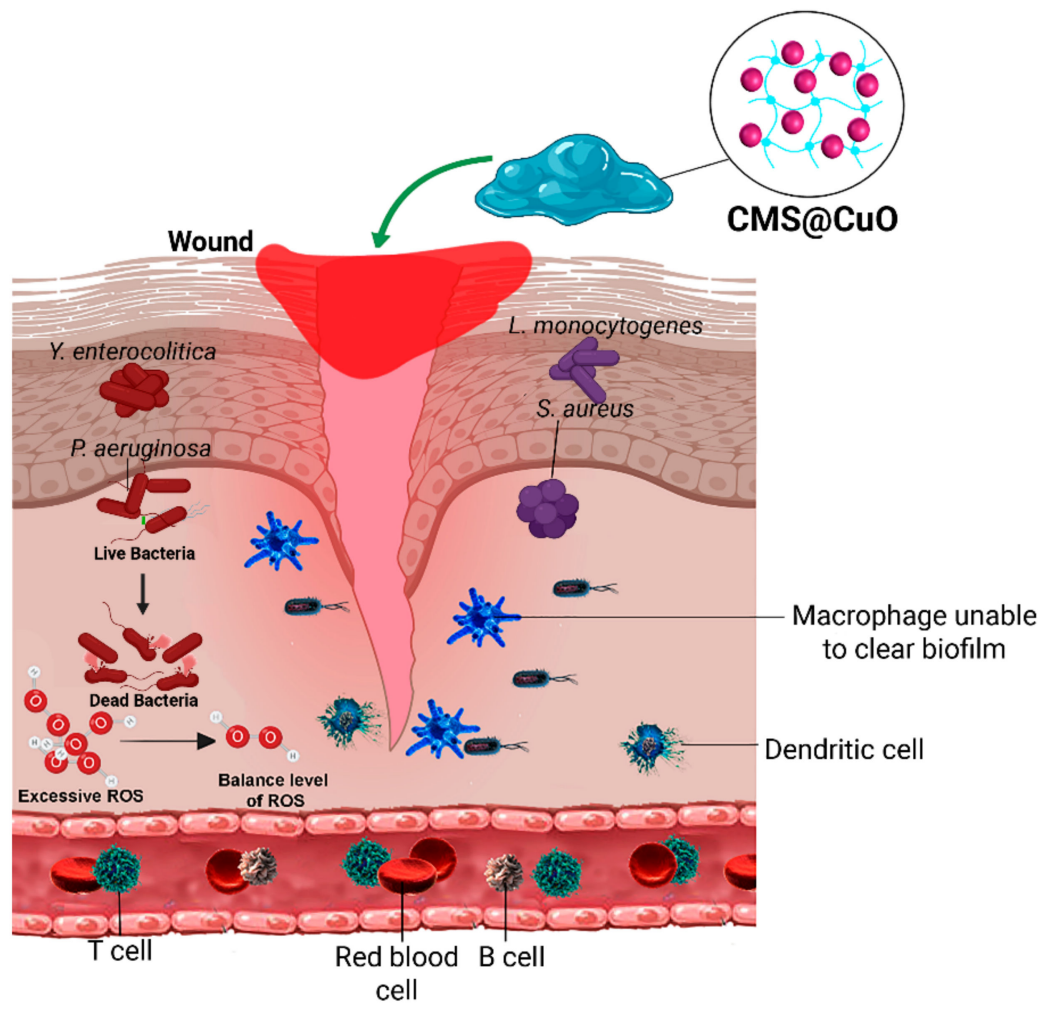

Figure 8. Schematic of the application of a nanocomposite hydrogel with antibacterial and antioxidant properties to promote wound healing.

\section{Materials and Methods}

\subsection{Materials}

Corn starch (practical grade with $24.35 \%$ amylose and $13.27 \%$ moisture content) was acquired from Kimia Eksir company (Tehran, Iran). Sodium hydroxide, isopropanol, monochloroacetic acid (MCA), methanol, citric acid (CA), and 2,2-diphenyl-1-picrylhydrazyl (DPPH·) were purchased from Merck KGaA (Darmstadt, Germany) and used without purification. Spherical $\mathrm{CuO}$ nanoparticles, each with a mean diameter of $\sim 30 \mathrm{~nm}$, were acquired from Neutrino Company (Tehran, Iran). All Gram-negative and Gram-positive bacteria were purchased from Persian Type Culture Collection (PTCC; Tehran, Iran) and the American type culture collection (ATCC; Manassas, VA, USA).

\subsection{Synthesis of Sodium Carboxymethyl Starch (CMS)}

Sodium carboxymethyl starch (CMS) was synthesized using a previously-reported method with minor modifications [16] (Figure 9a). Corn starch (1 g) was dispersed and stirred in $15 \mathrm{~mL}$ isopropanol for $15 \mathrm{~min}$. Sodium hydroxide $(1.2 \mathrm{~g})$ was slowly added to the solution, with continuous stirring at $40{ }^{\circ} \mathrm{C}$ for $1 \mathrm{~h}$. This was followed by the addition of $1.36 \mathrm{~g}$ of monochloroacetic acid to the solution, with continuous stirring for another $1 \mathrm{~h}$. A white precipitate of CMS was subsequently obtained. The precipitate was centrifuged, washed several times with $80 \%$ methanol solution, and dried at $40{ }^{\circ} \mathrm{C}$ for $24 \mathrm{~h}$. The degree of substitution (DS $=0.87$ ) of the CMS was calculated by the direct titration technique [68]. 

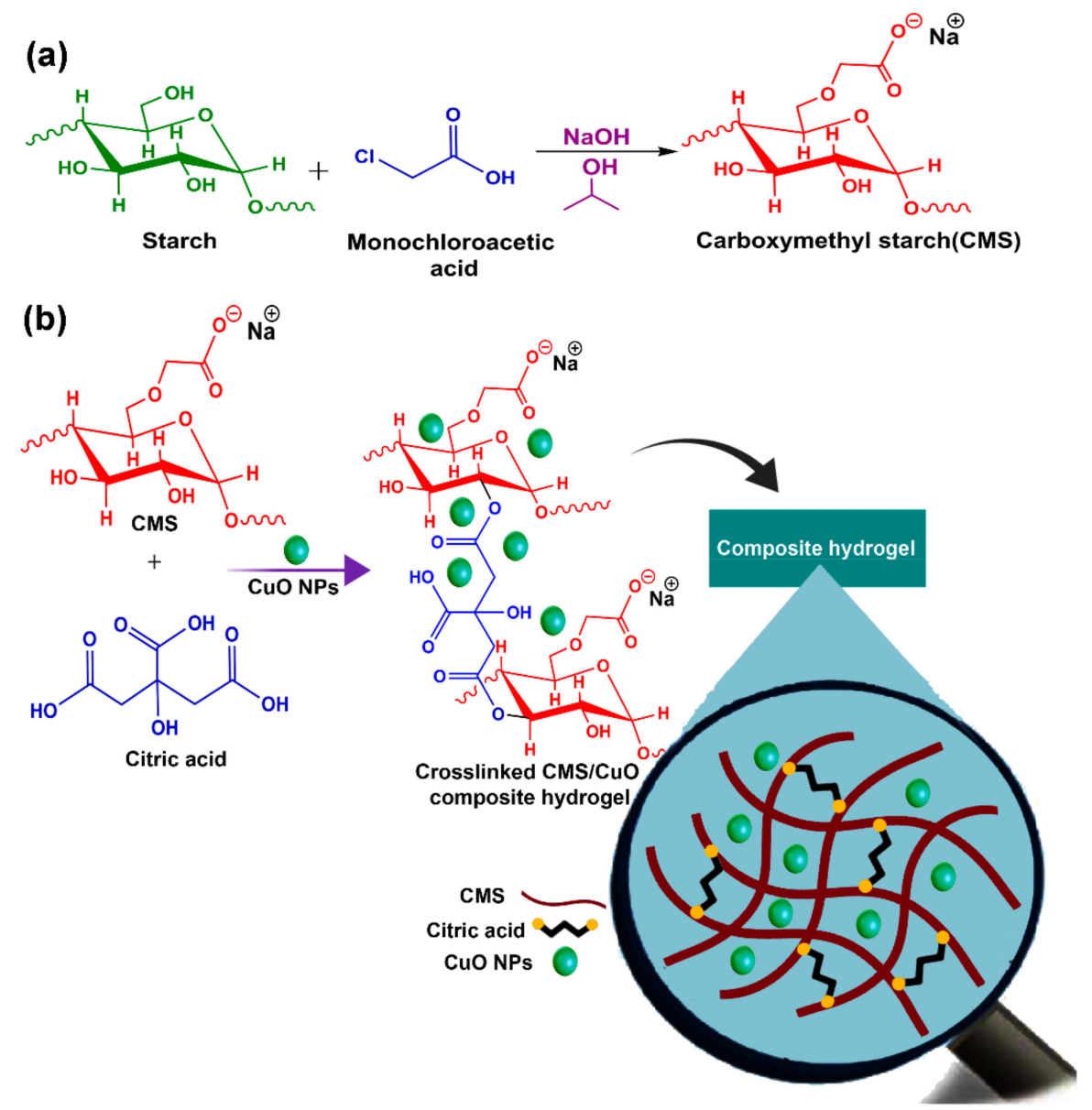

Figure 9. Schematic of the preparation of (a) sodium carboxymethyl starch (CMS) and (b) nanocomposite hydrogels that consists of $\mathrm{CuO}$ nanoparticles (NPs) dispersed within the citric acid crosslinked CMS polymer matrix.

\subsection{Fabrication of CMS@CuO Nanocomposite Hydrogels}

Nanocomposite hydrogels consisting of a sodium CMS matrix and $\mathrm{CuO}$ nanoparticles (CMS@CuO) were fabricated using the solution-casting method (Figure 9b). For small-scale synthesis, $1 \mathrm{~g}$ of CMS powder was mixed with $50 \mathrm{~mL}$ of distilled water and stirred at room temperature until completely dissolved. The $\mathrm{CuO}$ nanoparticles ( $2 \mathrm{wt} . \%$ and $4 \mathrm{wt} . \%)$ were added to the solution and sonicated at ambient temperature for $10 \mathrm{~min}$. The citric acid (15 wt.\% to the CMS) was used as the crosslinking agent and gradually added to the reaction vessel. The solution was kept at ambient temperature for $30 \mathrm{~min}$. The mixture was poured into plastic plates and dried at $30^{\circ} \mathrm{C}$. In the present work, $\mathrm{CMS} @ \mathrm{CuO}$ nanocomposite hydrogels with $2 \mathrm{wt} . \%$ or $4 \mathrm{wt} . \% \mathrm{CuO}$ nanoparticles were fabricated. A control hydrogel was also prepared using crosslinked CMS without incorporation of $\mathrm{CuO}$ nanoparticles.

\subsection{Characterization}

The prepared nanocomposite hydrogels were examined using Fourier transform infrared spectroscopy (FTIR) (Equinox 55, Bruker Optik GmbH, Leipzig, Germany) in the wavenumber range of $4000-400 \mathrm{~cm}^{-1}$. A field emission scanning electron microscope coupled with energy dispersive X-ray analysis (FESEM/EDS) (MIRA 3-XMU, Tescan, Kohoutovice, Czech Republic) was used for evaluating the surface morphology of the synthesized materials. The crystallinity of materials was examined using X-ray diffraction (XRD) (D8 Advance X-ray diffractometer, Bruker Optik GmbH, Leipzig, Germany). Thermogravimetric analysis (TG 209F3, NETZSCH, Selb, Germany) was used to investigate the thermal stability of the materials. Ultraviolet-visible light absorption spectroscopy (Cecil 
5000 series UV-vis spectrometer (Cecil Instruments Ltd., Cambridge, UK) was used for evaluating the antioxidant activities of materials.

\subsection{Swelling Study}

Fluid absorbance was evaluated by first weighing the dried hydrogel specimens at $40{ }^{\circ} \mathrm{C}\left(\mathrm{W}_{0}\right.$, primary mass $)$. The dried specimens were placed in glass vessels with $10 \mathrm{~mL}$ distilled water at room temperature for $1 \mathrm{~h}$. The hydrated hydrogel specimens were removed from the glass vessels, gently wiped with filter paper to eliminate excess water, and re-weighed $\left(\mathrm{W}_{\mathrm{s}}\right.$, swollen mass). Weight values were used to calculate the degree of swelling (SD, in \%) using the following Equation (1) [28].

$$
\mathrm{SD}(\%)=\left(\left(\mathrm{W}_{\mathrm{s}}-\mathrm{W}_{0}\right) / \mathrm{W}_{0}\right) \times 100 \%
$$

\subsection{Antioxidant Study}

The hydrogel specimens were placed in beakers containing distilled water for $24 \mathrm{~h}$. One milliliter of the hydrogel solution was mixed with $2 \mathrm{~mL}$ of methanolic DPPH. solution $(25 \mu \mathrm{mol} / \mathrm{L})$ and kept in a dark place for $30 \mathrm{~min}$. Solution absorbance was measured at $517 \mathrm{~nm}$ using the aforementioned UV-vis spectrophotometer. The antioxidant activity of pristine $\mathrm{CMS}$ and the $\mathrm{CuO}$ nanoparticles were also measured for comparison. Inhibition of $\mathrm{DPPH}$ (in \%) was measured using the following Equation (2) [49]:

$$
\text { DPPH inhibition }(\%)=\left(A_{b}-A_{s} / A_{b}\right) \times 100
$$

where $A_{b}$ is the methanolic DPPH absorption (blank) and $A_{s}$ is the absorption of the sample solution.

\subsection{Antibacterial Study}

The Kirby-Bauer test (disk-diffusion method) was used to compare the antibacterial efficacy of CuO nanoparticles, CMS, CMS@2\%CuO, and CMS@4\%CuO against bacterial growth. Several Gram-positive bacteria (Listeria monocytogenes, Enterococcus faecalis, Staphylococcus aureus and methicillin-resistant Staphylococcus aureus) and Gram-negative bacteria (Salmonella enterica, Pseudomonas aeruginosa, Escherichia coli, and Yersinia enterocolitica) were used to test the antibacterial efficacy of the hydrogel nanocomposites. The Lyophilized bacteria were revived in their corresponding medium at $37^{\circ} \mathrm{C}$ for $24 \mathrm{~h}$. After incubation, $10 \mu \mathrm{L}$ of each microbial suspension was added to culture medium-containing agar and incubated at $37^{\circ} \mathrm{C}$ for $24 \mathrm{~h}$. For determination of antimicrobial activity, 4-6 identical colonies of each microbial species were inoculated into tubes containing Muller Hinton broth or tryptic soy broth. The inoculated media was incubated at $37^{\circ} \mathrm{C}$ for $4 \mathrm{~h}$. At the end of the incubation period, the optical density of each medium was read at $625 \mathrm{~nm}$. The absorbance of media was adjusted to $0.08-0.1$ with a final cell density of $1.5 \times 10^{8}$ colony forming units $(\mathrm{CFU}) / \mathrm{mL}$. These microbial suspensions were spread on Muller Hinton agar or tryptic soy agar using a sterile cotton swab. Sterile CuO NPs, CMS, CMS@2\%CuO, and CMS@4\%CuO (8 mm diameter) were inoculated on agar-containing Petri plates and incubated at $4{ }^{\circ} \mathrm{C}$ to enable diffusion of compounds derived from the tested specimens into the medium. The plates were incubated at $37^{\circ} \mathrm{C}$ for $24 \mathrm{~h}$ prior to measuring the diameter of the inhibition zones on the surface of the agar. Each test was performed in triplicate and the results were reported as means \pm standard deviations.

\subsection{In Vitro Cell Cytotoxicity Study}

The cytotoxicity of the fabricated nanocomposite hydrogels and CMS on human dermal fibroblast (HDF-with NCBIcode of C645; Cell Bank of Pasteur Institute of Iran, Tehran, Iran) was evaluated using the MTT (3-(4,5-dimethylthiazol-2-yl)-2,5-diphenyltetrazolium bromide) assay after incubation for 24,48 and $72 \mathrm{~h}$. The stock solution of the specimens was prepared in dimethyl sulfoxide (DMSO), and 25, 50, 100, 200, 600, 800, and $1600 \mu \mathrm{g}$ $\mathrm{mL}^{-1}$ of the specimens were prepared using Dulbecco's Modified Eagle Medium. The cyto- 
toxicity of DMSO, the solvent of nanocomposite hydrogels and CMS, was also determined. Untreated cells were used as the control. The viability of the cells exposed to the samples was calculated using the following Equation (3):

$$
\text { Viability } \%=\frac{\text { Absorbance in the Treatment Group }}{\text { Absorbance in Control Group }} \times 100
$$

\subsection{In Vivo Wound Healing Study}

The efficacy of the hydrogels on wound healing was evaluated using a small animal model. Male Wistar rats were randomly divided into three groups: control, CMS, and CMS@2 $\% \mathrm{CuO}$. The rats were anesthetized with an intraperitoneal injection of $10 \mathrm{mg} / \mathrm{kg}$ Rampan (Bayer, Leverkusen, Germany) and $100 \mathrm{mg} / \mathrm{kg}$ ketamine hydrochloride (Gedeon Richter, Budapest, Hungary). Hair from the back of each rat was shaved and cleaned. A full-thickness incision ( $35 \mathrm{~mm}$ in length) was created at a distance of $1.5 \mathrm{~cm}$ on the right of the dorsal midline of each rat (Figure 7). Wounds in the CMS and CMS@2\%CuO groups were treated with CMS and CMS@2\%CuO hydrogels, respectively. The results were compared to the untreated control group. Wound length and wound surface area were used for healing evaluation. For surface area measurement, each rat was anesthetized with ether inhalation. A trace of each wound surface was made with tracing paper affixed to a millimeter paper. Squares located inside the trace were counted. The surface area was measured on 0 (surgery day), 3, 5, 7, 9, and 13 days after surgery. The percentage of wound healing percentage was determined using the following Equation (4) [69].

$$
\text { Wound healing }(\%)=\frac{[\text { Wound surface area on }(0) \text { days }]-[\text { Wound surface area on }(x) \text { days }]}{[\text { Wound surface area on }(0) \text { days }]} \times 100
$$

\subsection{Statistical Analysis}

Data were expressed as means and standard deviations. For each experiment that required statistical analysis, data in the respective groups were tested for their normality (Shapiro-Wilk test) and equal variance assumptions (modified Levene test). If those assumptions appeared to have been violated, the data were non-linearly transformed to satisfy those assumptions prior to the use of parametric statistical methods. For each data set, results derived from the associated groups were analyzed using a one-factor analysis of variance. Post-hoc pairwise comparisons were performed using the Tukey test. For all tests, statistical significance was present at $\alpha=0.05$.

\section{Conclusions}

In the present work, CMS and CMS@CuO hydrogels were fabricated by solutioncasting and investigated as potential wound healing. The hydrogels were characterized using different methods to determine their physicochemical properties. The CMS-based hydrogels containing $\mathrm{CuO}$ nanoparticles exhibited a high swelling degree (above $80 \%$ ) when crosslinked with an optimized amount of citric acid (15 wt. \%). The CMS@CuO nanocomposite hydrogels showed good antibacterial activity against eight types of Gram-negative and -positive bacteria that are pathogenic to the human body. Maximum antioxidant activity was observed in hydrogels containing $4 \mathrm{wt} . \% \mathrm{CuO}$ nanoparticles. Low cytotoxicity against human fibroblasts was observed in the nanocomposite hydrogel that contains $2 \mathrm{wt} . \% \mathrm{CuO}$ nanoparticles. Evaluation of in vivo wound healing using a rat model indicates that skin wounds treated with the CMS@2\%CuO nanocomposite hydrogel healed faster than wounds treated with the pure CMS hydrogel. Incorporation of $\mathrm{CuO}$ nanoparticles into CMS improved antibacterial and antioxidant activities. The CMS@CuO nanocomposite hydrogel has the potential to be used as a skin wound dressing in tissue regeneration.

Supplementary Materials: Supplementary data are available online at https:/ /www.mdpi.com/ 1422-0067/22/5/2531/s1, Figure S1: FTIR spectrum (a), XRD pattern (b), EDS spectrum (c), and TGA curve (d) of the CMS@4\%CuO nanocomposite hydrogel, Table S1: UV-vis data of antioxidant activities of CMS, CuO nanoparticles, CMS@2\%CuO, and CMS@4\%CuO nanocomposite hydrogels 
in methanolic DPPH. solution. Ab, the absorbance of DPPH solution at $517 \mathrm{~nm}$; As, the absorbance of each sample in DPPH solution at $517 \mathrm{~nm}$.

Author Contributions: Methodology, Z.A.; investigation, Z.A.; writing-original draft preparation, E.N.Z.; writing—review and editing, E.N.Z., F.S., I.G., F.R.T., and P.M.; supervision, E.N.Z.; project administration, E.N.Z., F.S., I.G. and P.M. All authors have read and agreed to the published version of the manuscript.

Funding: This research received no external funding.

Institutional Review Board Statement: The experimental protocol was approved by the Research and Ethics Committee of Damghan University.

Acknowledgments: E. N. Zare, F. Salimi, and I. Goudarzi are thankful to Damghan University for the financial support of current research.

Conflicts of Interest: The authors declare no conflict of interest.

\section{References}

1. Strecker-McGraw, M.K.; Jones, T.R.; Baer, D.G. Soft tissue wounds and principles of healing. Emerg. Med. Clin. North Am. 2007, 25, 1-22. [CrossRef]

2. Al Guo, S.; DiPietro, L.A. Factors affecting wound healing. J. Dent. Res. 2010, 89, 219-229. [CrossRef]

3. Prasad, S.; Gupta, S.C.; Tyagi, A.K. Reactive oxygen species (ROS) and cancer: Role of antioxidative nutraceuticals. Cancer Lett. 2017, 387, 95-105. [CrossRef] [PubMed]

4. Shi, S.; Xue, F. Current antioxidant treatments in organ transplantation. Oxid. Med. Cell. Longev. 2016, 2016, 8678510. [CrossRef]

5. Marrazzo, P.; O'Leary, C. Repositioning natural antioxidants for therapeutic applications in tissue engineering. Bioengineering 2020, 7, 104. [CrossRef] [PubMed]

6. Martins-Green, M.; Saeed, S. Role of Oxidants and Antioxidants in Diabetic Wound Healing. In Wound Healing, Tissue Repair, and Regeneration in Diabetes; Elsevier: Amsterdam, The Netherlands, 2020; pp. 13-38.

7. Xiao, Y.; Reis, L.A.; Feric, N.; Knee, E.J.; Gu, J.; Cao, S.; Laschinger, C.; Londono, C.; Antolovich, J.; McGuigan, A.P. Diabetic wound regeneration using peptide-modified hydrogels to target re-epithelialization. Proc. Natl. Acad. Sci. USA 2016, 113, E5792-E5801. [CrossRef] [PubMed]

8. Wölfle, U.; Seelinger, G.; Bauer, G.; Meinke, M.C.; Lademann, J.; Schempp, C.M. Reactive molecule species and antioxidative mechanisms in normal skin and skin aging. Skin Pharmacol. Physiol. 2014, 27, 316-332. [CrossRef] [PubMed]

9. Zafar, M.S.; Quarta, A.; Marradi, M.; Ragusa, A. Recent developments in the reduction of oxidative stress through antioxidant polymeric formulations. Pharmaceutics 2019, 11, 505. [CrossRef]

10. Chapple, I.L.C.; Matthews, J.B. The role of reactive oxygen and antioxidant species in periodontal tissue destruction. Periodontology 2007, 43, 160-232. [CrossRef]

11. Agarwal, A.; Aponte-Mellado, A.; Premkumar, B.J.; Shaman, A.; Gupta, S. The effects of oxidative stress on female reproduction: A review. Reprod. Biol. Endocrinol. 2012, 10, 1-31. [CrossRef]

12. Kurahashi, T.; Fujii, J. Roles of antioxidative enzymes in wound healing. J. Dev. Biol. 2015, 3, 57-70. [CrossRef]

13. Kennedy, J.F.; Knill, C.J.; Thorley, M. Natural Polymers for Healing Wounds. In Recent Advances in Environmentally Compatible Polymers; Elsevier: Amsterdam, The Netherlands, 2001; pp. 97-104.

14. Mogoşanu, G.D.; Grumezescu, A.M. Natural and synthetic polymers for wounds and burns dressing. Int. J. Pharm. 2014, 463, 127-136. [CrossRef]

15. Valencia, G.A.; Zare, E.N.; Makvandi, P.; Gutiérrez, T.J. Self-Assembled Carbohydrate Polymers for Food Applications: A Review. Compr. Rev. Food Sci. Food Saf. 2019, 18, 2009-2024. [CrossRef]

16. Spychaj, T.; Wilpiszewska, K.; Zdanowicz, M. Medium and high substituted carboxymethyl starch: Synthesis, characterization and application. Starch 2013, 65, 22-33. [CrossRef]

17. Liu, J.; Ming, J.; Li, W.; Zhao, G. Synthesis, characterisation and in vitro digestibility of carboxymethyl potato starch rapidly prepared with microwave-assistance. Food Chem. 2012, 133, 1196-1205. [CrossRef]

18. Ragheb, A.A.; El-Sayiad, H.S.; Hebeish, A. Preparation and characterization of carboxymethyl starch (CMS) products and their utilization in textile printing. Starch 1997, 49, 238-245. [CrossRef]

19. Friciu, M.M.; Le, T.C.; Ispas-Szabo, P.; Mateescu, M.A. Carboxymethyl starch and lecithin complex as matrix for targeted drug delivery: I. Monolithic Mesalamine forms for colon delivery. Eur. J. Pharm. Biopharm. 2013, 85, 521-530. [CrossRef] [PubMed]

20. Ounkaew, A.; Kasemsiri, P.; Jetsrisuparb, K.; Uyama, H.; Hsu, Y.-I.; Boonmars, T.; Artchayasawat, A.; Knijnenburg, J.T.N.; Chindaprasirt, P. Synthesis of nanocomposite hydrogel based carboxymethyl starch/polyvinyl alcohol/nanosilver for biomedical materials. Carbohydr. Polym. 2020, 248, 116767. [CrossRef] [PubMed]

21. Ismail, N.A.; Amin, K.A.M.; Razali, M.H. Gellan gum incorporating titanium dioxide nanoparticles biofilm as wound dressing: Physicochemical, mechanical, antibacterial properties and wound healing studies. Mater. Sci. Eng. 2019, 103, 109770. [CrossRef] [PubMed] 
22. Zhou, M.; Tian, M.; Li, C. Copper-based nanomaterials for cancer imaging and therapy. Bioconjug. Chem. 2016, 27, 1188-1199. [CrossRef] [PubMed]

23. Ahmadian, Y.; Bakravi, A.; Hashemi, H.; Namazi, H. Synthesis of polyvinyl alcohol/CuO nanocomposite hydrogel and its application as drug delivery agent. Polym. Bull. 2019, 76, 1967-1983. [CrossRef]

24. Sankar, R.; Baskaran, A.; Shivashangari, K.S.; Ravikumar, V. Inhibition of pathogenic bacterial growth on excision wound by green synthesized copper oxide nanoparticles leads to accelerated wound healing activity in Wistar Albino rats. J. Mater. Sci. Mater. Med. 2015, 26, 214. [CrossRef] [PubMed]

25. Grigore, M.E.; Biscu, E.R.; Holban, A.M.; Gestal, M.C.; Grumezescu, A.M. Methods of synthesis, properties and biomedical applications of $\mathrm{CuO}$ nanoparticles. Pharmaceuticals 2016, 9, 75. [CrossRef] [PubMed]

26. Gutha, Y.; Pathak, J.L.; Zhang, W.; Zhang, Y.; Jiao, X. Antibacterial and wound healing properties of chitosan/poly (vinyl alcohol)/zinc oxide beads (CS/PVA/ZnO). Int. J. Biol. Macromol. 2017, 103, 234-241. [CrossRef]

27. Baghaie, S.; Khorasani, M.T.; Zarrabi, A.; Moshtaghian, J. Wound healing properties of PVA/starch/chitosan hydrogel membranes with nano Zinc oxide as antibacterial wound dressing material. J. Biomater. Sci. Polym. Ed. 2017, 28, 2220-2241. [CrossRef]

28. Capanema, N.S.V.; Mansur, A.A.P.; de Jesus, A.C.; Carvalho, S.M.; de Oliveira, L.C.; Mansur, H.S. Superabsorbent crosslinked carboxymethyl cellulose-PEG hydrogels for potential wound dressing applications. Int. J. Biol. Macromol. 2018, 106, 1218-1234. [CrossRef]

29. Basu, P.; Narendrakumar, U.; Arunachalam, R.; Devi, S.; Manjubala, I. Characterization and evaluation of carboxymethyl cellulose-based films for healing of full-thickness wounds in normal and diabetic rats. ACS Omega 2018, 3, 12622-12632. [CrossRef]

30. Ahmed, A.; Niazi, M.B.K.; Jahan, Z.; Ahmad, T.; Hussain, A.; Pervaiz, E.; Janjua, H.A.; Hussain, Z. In-vitro and in-vivo study of superabsorbent PVA/Starch/g-C3N4/Ag@ TiO2 NPs hydrogel membranes for wound dressing. Eur. Polym. J. 2020, 130, 109650. [CrossRef]

31. Bi, Y.; Liu, M.; Wu, L.; Cui, D. Synthesis of carboxymethyl potato starch and comparison of optimal reaction conditions from different sources. Polym. Adv. Technol. 2008, 19, 1185-1192. [CrossRef]

32. Avval, M.E.; Moghaddam, P.N.; Fareghi, A.R. Modification of starch by graft copolymerization: A drug delivery system tested for cephalexin antibiotic. Starch 2013, 65, 572-583. [CrossRef]

33. Muthuvel, A.; Jothibas, M.; Manoharan, C. Synthesis of copper oxide nanoparticles by chemical and biogenic methods: Photocatalytic degradation and in vitro antioxidant activity. Nanotechnol. Environ. Eng. 2020, 5, 1-19. [CrossRef]

34. Reddy, S.; Swamy, B.E.K.; Jayadevappa, H. CuO nanoparticle sensor for the electrochemical determination of dopamine. Electrochim. Acta 2012, 61, 78-86. [CrossRef]

35. Zhang, B.; Gong, H.; Lü, S.; Ni, B.; Liu, M.; Gao, C.; Huang, Y.; Han, F. Synthesis and characterization of carboxymethyl potato starch and its application in reactive dye printing. Int. J. Biol. Macromol. 2012, 51, 668-674. [CrossRef] [PubMed]

36. Sundar, S.; Venkatachalam, G.; Kwon, S.J. Biosynthesis of copper oxide (CuO) nanowires and their use for the electrochemical sensing of dopamine. Nanomaterials 2018, 8, 823. [CrossRef] [PubMed]

37. Shi, R.; Bi, J.; Zhang, Z.; Zhu, A.; Chen, D.; Zhou, X.; Zhang, L.; Tian, W. The effect of citric acid on the structural properties and cytotoxicity of the polyvinyl alcohol/starch films when molding at high temperature. Carbohydr. Polym. 2008, 74, 763-770. [CrossRef]

38. Zhang, B.; Wei, B.; Hu, X.; Jin, Z.; Xu, X.; Tian, Y. Preparation and characterization of carboxymethyl starch microgel with different crosslinking densities. Carbohydr. Polym. 2015, 124, 245-253. [CrossRef]

39. Zhang, B.; Tao, H.; Wei, B.; Jin, Z.; Xu, X.; Tian, Y. Characterization of different substituted carboxymethyl starch microgels and their interactions with lysozyme. PLoS ONE 2014, 9, e114634. [CrossRef]

40. Manjari, G.; Saran, S.; Arun, T.; Rao, A.V.B.; Devipriya, S.P. Catalytic and recyclability properties of phytogenic copper oxide nanoparticles derived from Aglaia elaeagnoidea flower extract. J. Saudi Chem. Soc. 2017, 21, 610-618. [CrossRef]

41. Suresh, S.; Karthikeyan, S.; Jayamoorthy, K. FTIR and multivariate analysis to study the effect of bulk and nano copper oxide on peanut plant leaves. J. Sci. Adv. Mater. Devices 2016, 1, 343-350. [CrossRef]

42. Wang, C.-Y.; Makvandi, P.; Zare, E.N.; Tay, F.R.; Niu, L.N. Advances in Antimicrobial Organic and Inorganic Nanocompounds in Biomedicine. Adv. Ther. 2020, 3, 2000024. [CrossRef]

43. Jamaledin, R.; Yiu, C.K.Y.; Zare, E.N.; Niu, L.; Vecchione, R.; Chen, G.; Gu, Z.; Tay, F.R.; Makvandi, P. Advances in antimicrobial microneedle patches for combating infections. Adv. Mater. 2020, 32, 2002129. [CrossRef] [PubMed]

44. Schäfer, M.; Werner, S. Oxidative stress in normal and impaired wound repair. Pharmacol. Res. 2008, 58, 165-171. [CrossRef]

45. Bölgen, N.; Demir, D.; Yalçın, M.S.; Özdemir, S. Development of Hypericum perforatum oil incorporated antimicrobial and antioxidant chitosan cryogel as a wound dressing material. Int. J. Biol. Macromol. 2020, 161, 1581-1590. [CrossRef]

46. Hassan, M.A.; Tamer, T.M.; Valachová, K.; Omer, A.M.; El-Shafeey, M.; Eldin, M.S.M.; Šoltés, L. Antioxidant and antibacterial polyelectrolyte wound dressing based on chitosan/hyaluronan/phosphatidylcholine dihydroquercetin. Int. J. Biol. Macromol. 2021, 166, 18-31. [CrossRef]

47. Romero-Montero, A.; Labra-Vázquez, P.; del Valle, L.J.; Puiggalí, J.; García-Arrazola, R.; Montiel, C.; Gimeno, M. Development of an antimicrobial and antioxidant hydrogel/nano-electrospun wound dressing. RSC Adv. 2020, 10, 30508-30518. [CrossRef]

48. Zare, E.N.; Lakouraj, M.M.; Mohseni, M.; Motahari, A. Multilayered electromagnetic bionanocomposite based on alginic acid: Characterization and biological activities. Carbohydr. Polym. 2015, 130, 372-380. [CrossRef] 
49. Janani, N.; Zare, E.N.; Salimi, F.; Makvandi, P. Antibacterial tragacanth gum-based nanocomposite films carrying ascorbic acid antioxidant for bioactive food packaging. Carbohydr. Polym. 2020, 247, 116678. [CrossRef]

50. Das, D.; Nath, B.C.; Phukon, P.; Dolui, S.K. Synthesis and evaluation of antioxidant and antibacterial behavior of CuO nanoparticles. Colloids Surf. Biointerfaces 2013, 101, 430-433. [CrossRef]

51. Syafiq, R.; Sapuan, S.M.; Zuhri, M.Y.M.; Ilyas, R.A.; Nazrin, A.; Sherwani, S.F.K.; Khalina, A. Antimicrobial activities of starch-based biopolymers and biocomposites incorporated with plant essential oils: A review. Polymers 2020, 12, 2403. [CrossRef]

52. Ahamed, M.; Alhadlaq, H.A.; Khan, M.A.; Karuppiah, P.; Al-Dhabi, N.A. Synthesis, characterization, and antimicrobial activity of copper oxide nanoparticles. J. Nanomater. 2014, 2014, 1-5. [CrossRef]

53. Makvandi, P.; Wang, C.; Zare, E.N.; Borzacchiello, A.; Niu, L.; Tay, F.R. Metal-based nanomaterials in biomedical applications: Antimicrobial activity and cytotoxicity aspects. Adv. Funct. Mater. 2020, 30, 1910021. [CrossRef]

54. Abudayyak, M.; Guzel, E.; Özhan, G. Cupric Oxide Nanoparticles Induce Cellular Toxicity in Liver and Intestine Cell Lines. Adv. Pharm. Bull. 2020, 10, 213. [CrossRef]

55. Katsumiti, A.; Thorley, A.J.; Arostegui, I.; Reip, P.; Valsami-Jones, E.; Tetley, T.D.; Cajaraville, M.P. Cytotoxicity and cellular mechanisms of toxicity of CuO NPs in mussel cells in vitro and comparative sensitivity with human cells. Toxicol. In Vitro 2018, 48, 146-158. [CrossRef]

56. Borkow, G.; Gabbay, J. Copper as a biocidal tool. Curr. Med. Chem. 2005, 12, 2163-2175. [CrossRef]

57. Sen, C.K.; Khanna, S.; Venojarvi, M.; Trikha, P.; Ellison, E.C.; Hunt, T.K.; Roy, S. Copper-induced vascular endothelial growth factor expression and wound healing. Am. J. Physiol. Circ. Physiol. 2002, 282, H1821-H1827. [CrossRef]

58. Ahmed, Z.; Briden, A.; Hall, S.; Brown, R.A. Stabilisation of cables of fibronectin with micromolar concentrations of copper: In vitro cell substrate properties. Biomaterials 2004, 25, 803-812. [CrossRef]

59. Rucker, R.B.; Kosonen, T.; Clegg, M.S.; Mitchell, A.E.; Rucker, B.R.; Uriu-Hare, J.Y.; Keen, C.L. Copper, lysyl oxidase, and extracellular matrix protein cross-linking. Am. J. Clin. Nutr. 1998, 67, 996S-1002S. [CrossRef]

60. Lansdown, A.B.G.; Sampson, B.; Rowe, A. Sequential changes in trace metal, metallothionein and calmodulin concentrations in healing skin wounds. J. Anat. 1999, 195, 375-386. [CrossRef]

61. Mulder, G.D.; Patt, L.M.; Sanders, L.; Rosenstock, J.; Altman, M.I.; Hanley, M.E.; Duncan, G.W. Enhanced healing of ulcers in patients with diabetes by topical treatment with glycyl-l-histidyl-l-lysine copper. Wound Repair Regen. 1994, 2, 259-269. [CrossRef]

62. Shariati, A.; Moradabadi, A.; Azimi, T.; Ghaznavi-Rad, E. Wound healing properties and antimicrobial activity of platelet-derived biomaterials. Sci. Rep. 2020, 10, 1-9. [CrossRef]

63. Dev, S.K.; Choudhury, P.K.; Srivastava, R.; Sharma, M. Antimicrobial, anti-inflammatory and wound healing activity of polyherbal formulation. Biomed. Pharmacother. 2019, 111, 555-567. [CrossRef] [PubMed]

64. Levy, S.B. The challenge of antibiotic resistance. Sci. Am. 1998, 278, 46-53. [CrossRef]

65. Makvandi, P.; Ali, G.W.; Della Sala, F.; Abdel-Fattah, W.I.; Borzacchiello, A. Biosynthesis and characterization of antibacterial thermosensitive hydrogels based on corn silk extract, hyaluronic acid and nanosilver for potential wound healing. Carbohydr. Polym. 2019, 223, 115023. [CrossRef]

66. Casqueiro, J.; Casqueiro, J.; Alves, C. Infections in patients with diabetes mellitus: A review of pathogenesis. Indian J. Endocrinol. Metab. 2012, 16, S27.

67. Nikolopoulo, G.K.; Paraskevis, D.; Hatzitheodorou, E.; Moschidis, Z.; Sypsa, V.; Zavitsanos, X.; Kalapothaki, V.; Hatzakis, A Impact of hepatitis B virus infection on the progression of AIDS and mortality in HIV-infected individuals: A cohort study and meta-analysis. Clin. Infect. Dis. 2009, 48, 1763-1771. [CrossRef]

68. Benyerbah, N.; Ispas-Szabo, P.; Sakeer, K.; Chapdelaine, D.; Mateescu, M.A. Ampholytic and Polyelectrolytic Starch as Matrices for Controlled Drug Delivery. Pharmaceutics 2019, 11, 253. [CrossRef] [PubMed]

69. Goudarzi, I.; Hajizadeh, S.; Salmani, M.E.; Abrari, K. Pulsed electromagnetic fields accelerate wound healing in the skin of diabetic rats. Bioelectromagnetics 2010, 31, 318-323. [CrossRef] 